\title{
Traducciones francesas de José María Heredia, en La Revue des Deux Mondes *
}

$\mathbf{F}^{\mathrm{L}} 17$ de octubre de 1925, un grupo distinguidísimo se reunió en el Jardin del Luxemburgo, de París, para dedicar una estatua al sonetista más eminente de la época moderna: José María de Heredia. Además de la viuda del célebre cubano (el de habla francesa) y de sus hijas, Mme. Gérard d'Houville y Mme. Renée Doumic, acompañadas de sus ilustres maridos, Henri de Régnier y René Doumic, la concurrencia constaba del cuerpo diplomático de la América Hispánica, del ministro de Cuba, de una delegación de la Académie Française -que incluía, (entre otros, a Jean Richepin, Joseph Bédier y Porto-Riche) - y de muchos periodistas y poetas. Jean Richepin, que en nombre de la Comisión Heredia entregó el monumento a la ciudad, declaró que se habían obtenido los fondos por medio de una suscripción en la América Latina y en Francia.

Muchas confusiones biográficas se deben a que dos ilustres poetas, primos hermanos, ambos nacidos en Cuba, llevaron el mismo nombre y apellido. Heredia el mayor (1803-1839), el de habla castellana, murió tres años antes de nacer Heredia el menor, el de habla francesa (1842-1905). En 1851 su madre, viuda desde 1849, le envió a Francia, donde estudió hasta 1859, fecha de su regreso al país de nacimiento. Volvió a Francia en 1861. Cinco años más tarde, se publicaron seis sonetos suyos, en Le Parnasse contemporain, an-

* El autor aprovecha esta oportunidad para agradecer al Research Council de la Univers:ty de Nebraska los fondos con que realizó las investigaciones que se relatan en este trabajo. 
tología del movimiento literario llamado Le Parnasse, cuyo jefe era Leconte de Lisle. Después de éste, Heredia fué el miembro más leal a los principios de esta escuela. Debe su fama literaria al libro titulado, Les Trophées, colección de sonetos que se publicó en 1893. Al año siguiente entra en la Academia Francesa. Tradujo al francés la Verdadera historia de los sucesos de la conquista de la Nueva España, de Bernal Díaz del Castillo, La Monja Alférez, autobiografía de Catalina de Erauso, y Juan Soldado, de Fernán Caballero.

$\mathrm{La}$ dedicación de la estatua a Heredia el menor, relatada en el Mercure de France (el $1^{\text {s}}$ de noviembre de 1925) en la sección titulada Echos, ${ }^{1}$ impulsó a Camille Pitollet a escribir un artículo titulado, "L'autre José Maria de Heredia", que se publicó el 15 de diciembre en dicha revista. ${ }^{2}$ Pitollet se queja de que los franceses no se esfuercen por aprender el idioma de Cervantes, para poder conocer de primera mano las riquezas de la literatura hispánica, ${ }^{3}$ y asevera que la fama del otro Heredia, en Francia, "ne dépasse guère son nom." " Dice que los comentarios de Charles de Mazade $\mathrm{y}$ de Jean Jacques Ampère, sobre el poeta cubano, en La Revue des Deux Mondes resultan insignificantes, y que los juicios de Villemain en Le Génie de Pindare et la Poésie lyrique no son otra cosa que ejercicios retóricos pedantescos. ${ }^{5}$

La publicación en París (1893) de las Poesías líricas de Heredia el mayor, con un prólogo (xi-lxiii) por Elías Zerolo, se efectuó sin que crítica o público pareciera notarlo. ( No ha de olvidarse que en este mismo año se publicaron Les Trophées del Heredia de habla francesa!) La monografía sobre Heredia el mayor, por Enrique Piñeyro, que incluyó en su libro, Cómo acabó la dominación de España en América, 1908, no obtuvo más éxito, según Pitollet, que el prólogo de Zerolo. ${ }^{6}$

Con motivo de la publicación del libro de Piñeyro, Rubén Darío expresó el juicio siguiente que confirma ampliamente lo referido por Pitollet:

Para el parisiense no existe otro lugar habitable más que París. Se explica así la antigua y tradicional ignorancia de todo lo extranjero y el asombro curioso ante cualquier manifestaciónde superioridad extranjera. Ante un artista, ante un sabio, ante un talento extranjero, parecen preguntar: ¿Cómo, este hombre es extranjero y sin embargo tiene talento? 7 
Heredia, nos dice Menéndez y Pelayo, "es quizá el poeta ámericano más conocido en Europa, y el que de la crítica europea ha obtenido más unánimes y calurosos elogios, desde Listas hasta Villemain y Ampère." 8 Si Villemain hizo poco para hacer conocer a Heredia el mayor en Francia, no se puede decir lo mismo de Ampère y tampoco de Charles de Mazade. Este, en un estudio titulado "La société et la littérature à Cuba", publicado en La Rezue des Deux Mondes en $1851,{ }^{9}$ presenta, quizás por primera vez, el nombre del poeta Heredia al mundo literario de Francia. Dos años más tarde, Jean Jacques Ampère en la misma revista le consagra dos páginas relacionadas con su corta visita a México en $1852 .{ }^{10} \mathrm{Y}$ por fin ha de señalarse también en La Revue des Deux Mondes el simpático trabajo de Elisée Reclus, titulado "La Poésie et les poétes dans l'Amérique espagnole." 11 Sus traducciones en prosa de las poesías de Heredia - Mazade, "A Emilia", Ampère, "En el teocalli de Cholula", y Reclus, "En una tempestad"- que se encuentran interpoladas en el texto de dichos estudios serían, según mi leal saber y entender, las primeras que se publicaron en el idioma francés.

Conocen bien el nombre de Charles de Mazade los aficionados a las letras hispanoamericanas. Su artículo sobre el Facundo Quiroga, de Sarmiento, publicado en La Revue des Deux Mondes en 1846, ${ }^{12}$ que sobre este libro tan extraordinario llamó la atención del mundo ilustrado, condujo sin embargo a un conjunto de prejuicios y prevenciones, respecto a la civilización del Nuevo Mundo, los cuales a la larga hicieron más daño que bien, a la causa de la literatura hispanoamericana. El éxito de su artículo estimuló a este escritor conservador, con afinidades monárquicas, a encauzar por más de cuarenta años la mayor parte de sus energías de periodista, en una serie de escritos tan violentos como injustos contra la América Latina y los Estados Unidos. Al parecer de Mazade, las guerras de la Independencia no dieron otro resultado que el de reemplazar el orden impuesto por la monarquía española en una chusma inculta, semicivilizada y bárbara, de perezosos y léperos indios, mestizos, negros y mulatos, por una intolerable anarquía. Por eso no ha de sorprendernos que en el referido artículo ${ }^{13}$ sobre Cuba no vea en la poesía de Heredia sino lamentos hiperbólicos y elocuentes enojos de la imagindción contra le maitre espagnol. En la traducción si- 
guiente de los versos 31-72 de "A Emilia" (en que se omiten versos $44,51,53,54,59-61,64,65$ y partes de los versos $40,41,43$, $50,52,55,57,62)$ se echa de ver que Mazade conoce bien el español, pero le falta intuición poética y el instinto del ritmo. Sin embargo, el párrafo merece que se le señale, por ser tal vez la primera traducción de Heredia al francés.

Me voilá libre enfin: me voilá éloigné de maîtres et d'esclaves. Mais, Emilia, quel changement cruel! le vent d'hiver souffle furieux; sur ses ailes, une gelée aiguë vole et dévore le sol desseché. Une nuée épaisse couvre le soleil et ferme le ciel qui va se perdre à l'horizon douteux dans la mer sombre. Les arbres dépouillés gémissent. Aucun être vivant dans les campagnes; partout la solitude et la désolation. Est-ce donc là le séjour que je dois avoir en échange des champs lumineux, du ciel pur, de la verdure éternelle et des brises balsamiques du climat sous lequel mes yeux se sont ouverts à la lumière dans la douceur et la paix? . . Qu'importe?... Mes yeux no verront plus s'agiter la cime du palmiste dorée des rayons du soleil couchant. Mon oreille, au lieu de ton accent enchanteur, n'entend plus que les sons barbares d'un idiome étranger; mais au moins elle n'entendra pas le cri insolent du maître, ni le gémissement des esclaves, ni le sifflement du fouet, tous ces bruits qui empoisonnent l'air du Cuba!...14

El único disparate que se destaca en lo traducido, sè debe a la omisión de los siguientes versos que se anteponen a $Q u^{\prime}$ importe:

¿Entre dulzura y paz?... Estremecido

Me detengo, y agólpanse a mis ojos

Lágrimas de furor... ¿Qué importa? Emilia,

La ausencia de ellos da la impresión, por supuesto, de que se refiere al verso que acaba con las palabras "... dans la douceur et la paix".

Al admitir que los versos traducidos tienen la calidad de ser sinceros, Mazade afirma, no obstante, que se manifiesta en ellos la "émotion d'une âme ulcérée et outrée plutôt que véritablement libre..." Mazade concluye su juicio sobre Heredia, con estas palabras: "Ses vers son l'expression idéale et enflammée de ce vague instinct d'indépendance que fermente dans le coeur de la jeunesse cubanaise." 15 
Aunque Heredia sólo hubiera sentido "ce vague instinct d'indépendance", es inverosímil que hubiera tenido el gran poeta esa "âme ulcérée et outrée" y habría sido proscrito. Como lo formula Menéndez y Pelayo, es Heredia sobre todo "el poeta de sentimiento melancólico y de exaltación imaginativa"; "16 es decir, ante todo el autor de "En el teocalli de Cholula" y del "Niágara." Mazade, campeón de la Intervención francesa en México, espíritu seco y pragmático, a quien faltaba el sentido heroico, el amor a la libertad, y al parecer, imaginación poética, no pudo apreciar el sublime talento lírico del vate cubano. Para Mazade, la poesía de Heredia no era otra cosa que protestas contra el dominio español, y tales protestas no le inspiraban simpatía alguna. Mazade ejerció mucho tiempo gran influencia en Francia, por medio de sus articulos en La Revue des Deux Mondes. Durante más de treinta años se encargó de la Revista de la Quincena, en dicha revista. Por esto no podemos creer, como lo afirma Pitollet, que los comentarios de Mazade sobre Heredia resultaran insignificantes. Es lástima que fueran tan poco benévolos.

Lo que faltaba a Mazade en simpatía y amor al prójimo, le sobraba a Jean Jacques Ampère (1800-1864), hijo del distinguido físico y geómetra, André Marie Ampère. Jean Jacques estudió el sánscrito con Fauriel, quien le guió al estudio de idiomas, y de literatura y civilizaciones extranjeras. Según Sainte-Beuve, era tal su talento lingüístico que podía aprender cualquier idioma, incluso el chino, en poco tiempo. ${ }^{17}$ Sainte-Betuve, quien se llama a sí mismo "un élève d'Ampère", ${ }^{18}$ asistió fielmente a las conferencias que pronunció éste en el Collége de France, en 1833-1834. E1 ilustre crítico declara que era Ampère, entre todos los críticos e historiadores de literaturas extranjeras de su época, el más docto y competente. ${ }^{\mathbf{1 9}}$ Entró en la Academia Francesa en 1847.

Ampère hijo trabó amistad con Mme. Récamier, quien apadrinó el desarrollo de su savoir-vivre, y con Alexis de Tocqueville, quien le comunicó sus entusiasmos y simpatías por la joven democracia norteamericana. Sainte-Betuve declara que antes de escoger a Ampère como amigo predilecto, aquel ilustre historiador le había invitado a gozar de este privilegio. Agrega el crítico que no quiso 
aprovechar tan amable invitación y así le incumbió a Ampère el desempeño de este papel. ${ }^{20}$ Jean Jacques Ampère, hijo de aquel cuyo nombre conocen los choferes de todo el mundo, nunca llegó a ser más que un partidario algo platónico del republicanismo; sin embargo, al iniciarse la dictadura de Napoleón III, salió de Francia y no volvió a vivir en su patria.

En 1851-1852 efectuó Ampère el viaje a los Estados Unidos que describe en el libro titulado, Promenade en Amérique. Según Sainte-Beuve la serie de artículos, publicados en 1853 en La Revne des Deux Mondes, sobre la república norteamericana, no son otra cosa que la prolongación, in absentia, de las conversaciones que solia tener con de Tocqueville. ${ }^{21}$ Concluído su viaje por los Estados yanquis, fué a México: desembarcó en Veracruz a fines de febrero. Dió una conferencia en El Collège de France el 10 de mayo. Por consiguiente, su estancia en México duró poco tiempo.

Como era muy amante de la poesía (se dice que Ampère, antes de llegar a ser académico, participaba de incógnito antualmente en el certamen de poesía apadrinado por la Academia Francesa; ${ }^{22}$ y que escribió siete tragedias que nunca se representaron), no sorprende que las ruinas de Cholula, asentadas tan solemnemente dentro del magnífico triángulo isóceles que forman al Este, el Orizaba, y al Oeste el Popocatépetl y el Iztaccíhuatl ("the three most beatiful mountains in the world", "Fuijiyama and the Himalayas excepted", según Richard Halliburton), ${ }^{23}$ hicieran vibrar en toda amplitud la intuición poética de este francés tan impresionable y sensitivo.

Declara Ampère hacia el fin de las dos páginas consagradas a Heredia, que Manuel Carpio, "qui lui [Heredia] a été fort attaché", ${ }^{24}$ le informó que poco antes había tratado, sin éxito, de hallar la tumba del gran cubano. Esta referencia a Carpio nos permite suponer que muchos de sus informes sobre Heredia los debió al mismo Carpio, ${ }^{25}$ a quien admiraba Ampère hasta decir que "son. poème sur le Mexique est écrit en très beaux vers et bien supérieur à celui qu'a publié sur le même sujet Balbuena." 20 El paisaje de Cholula (en cuyas ruinas mustias y sombrías encontraba el viajero francés ese soplo romántico tan simpático a los jóvenes de su generación) evocó al espíritu de Ampère la obra maestra de Heredia: 
La grandeur de ce spectacle a inspiré de beaux vers à un poète, à un vrai poète, Heredia. Je vais essayer de traduire quelques-uns de ces vers d'une harmonie magnifique et donce comme le ciel qui les a vus naitre. Dépouiller cette poésie de l'éclat de la langue espagnole, c'est, je le sens trop, dépotiller un paysage tropical des splendeurs du soleil. ${ }^{2} \tau$

Ampère hizo una traducción en prosa de los versos 24 a 95 (se omiten versos 41-51) de "En el teocalli de Cholula" (1820), que, según el parecer de muchos, sería el primer poema verdaderamente romántico escrito en español. Para facilitar el cotejo de la traducción de Ampère con el original, pongo a continuación cada uno de los versos españoles, seguido de la traducción francesa.

Lo traducido por Ampère empieza con el verso número veinticuatro:

Era la tarde: su ligera brisa las alas en silencio ya plegaba y entre la hierba y árboles dormía, mientras el ancho sol su disco hundía

detrás de Tztaccihual. La nieve eterna, cual disuelta en mar de oro, semejaba temblar en torno de él; un arco inmenso que del empíreo en el cenit finaba como espléndido pórtico del cielo

de luz vestido y centelleante gloria, de sus últimos rayos recibía. los colores riquísimos. Su brillo desfalleciendo fué : la blanca luna y de Venus la estrella solitaria en el cielo desierto se veían. ¡Crepúsculo feliz! Hora nás bella que la alba noche y el brillante día, ¡ cuánto es dulce tu paz al alma mía!
24 C'était le soir; une brise légère

25 repliait ses ailes en silence,

26 et moi, je rêvais, couché sur l'herbe, parmi la verdure des arbres,

27 tandis que le soleil plongeait son disque

28 dertière POrizaba (sic). La niege éternelle

29 comme fondue en une mer d'or, semblait

30 tracer antour de lui un arc immense

31 qui montait jusqu'au zénith;

32 on entt dit un étincelant portique du ciel...

33

34

35 Puis cet eclat

36 s'évanouit. La blanche lune

37 et l'étoile solitaire de Vénus

38 se montraient dans le ciel.

39 Heure fortunée du crépuscule! plus belle

40 que la chaste nuit ou le jour brillant,

41 que ta paix est donce à mon âme! 
Se advierte que el traductor, despistado tal vez por la forma del verbo, interpreta mal el verso 26 . Que el sujeto de dormía sería su ligera brisa, más bien que yo, se comprueba en los versos omitidos (42-43) "hallábame sentado en la famosa Choluteca pirámide." Sería difícil concebir al poeta couché y sentado, al mismo tiempo. Otra cosa que sorprende aún más, es la substitución del Iztaccíhuatl (28) por el Orizaba. Heredia sentado en la Choluteca pirámide, con la mirada en el Poniente, ; claro que no podría ver ponerse el sol detrás del Orizaba!

¿Cuál sería la explicación de un cambio tan extraordinario? Se ofrecen varias hipótesis, entre las cuales está la de una falla mnemotécnica. Es de notar que el Orizaba se encuentra en los versos 12-14, omitidos por Ampère en su traducción:

\section{Nieve eternal corona las cabezas de Iztaccíhual purísimo, Orizaba y Popocatepec...}

¿Es posible que el Orizaba, el más famoso de los tres, y seguramente el menos repugnante, desde el punto de vista ortográfico, hubiera impresionado tanto a Ampère que inconscientemenee se hubiera grabado en su mente con tanta profundidad, que se realizó la transmutación, sin que se diera cuenta de ella el traductor? No es de negarse tal posibilidad. No obstante, nos parece más probable la suposición de que el error se debe al entusiasmo del viajero al contemplar, desde el teocalli, la majestūosa vista que describe como "le plus magnifique panorama de montagnes qui soit dans l'univer: la Femme Blanche, la Pierre-Fumante, l'Orizaba, voilá pour le Mexique les véritables, les incomparables pyramides." $28 \mathrm{Si}$ no se nombrara las tres montañas, se podría atribuir la equivocación a su imperfecto conocimiento de la geografía de México. Por lo dicho, esto no parece probable. Según nuestro leal juicio, no se debió a una casualidad, dicha equivocación, sino al contrario, a un deliberado propósito. Para transmitir en toda su totalidad las estáticas impresiones que sentía Ampère al contemplar la imponente vista, cuya asimilación poética le fué facilitada por todo lo nostálgico del ambiente arqueológico, ¿no se puede suponer que sustituyó deliberadamente al Iztaccíhuatl por el Orizaba? ${ }^{29}$ Habría podido justificar dicho intercambio de volcanes, por el razonamiento de que importaba más 
en el-asunto poesía que geografía. Además, sus lectores, ignorantes casi por completo de todo lo mexicano, no se darían cuenta del cambio.

De todos modos, con la omisión de los versos $42-52$ y sus detalles geográficos, inclusos

Hallábame sentado en la famosa

Choluteca pirámide... (42-43)

Ampère queda en libertad para reemplazar un volcán por otro, sin perjudicar, por lo menos a su parecer, los valores intrínsecos del poema. Por eso, no ha de sorprendernos su decisión de traducir dormía con yo como sujeto. Como Heredia, por lo tanto, no podría quedarse sentado en la pirámide y tenía necesariamente que estar en alguna parte, hizo que se acostara en la hierba, entre los árboles. Eso constituye una positiva licencia poética.

Al parecer, Ampère estimaba poco los versos 28-36, puesto que al traducirlos cambió el significado de los cinco primeros y omitió los demás, excepto una parte del último. La nieve eterna, y un arco inmenso, como sujetos de verbos diferentes, introducen conceptos tanto más distintos cuanto que el segundo depende del primero. Por último, s'évanouit (verso 36) no iguala de ninguna manera el sentido, a la vez paulatino y gradual, de desfalleciendo fué.

Bajó la noche en tanto. De la esfera el leve azul, obscuro y más obscuro

se fué tornando; la movible sombra de las nubes serenas, que volaban por el espacio en alas de la brisa, era visible en el tendido llano. Iztaccíhual purísimo volvía

del argentado rayo de la luna el plácido fulgor, y en el oriente bien como puntos de oro centellaban

mil estrellas y mil...;Oh! os saludo;
52 La nuit descendit enfin; $\ldots . . .$.

53 l'azul léger du ciel devint de plus en plus foncé;

$54 \ldots \ldots \ldots$. . les mobiles ombres

55 des nuées sereines qui volaient

56 à travers l'espace, emportées par les ailes de la brise,

57 passaient sur la plaine immense;

58 la neige limpide de l'Orizaba (sic) réflechissair

59 les calmes splendeurs de la lune

$60 \ldots \ldots \ldots \ldots$, et à l'orient,

61 comme des points dorés, scintillaient

62 mille et mille étoiles. Oh! je vous salue, 
fuentes de luz, que de la noche umbria ilumináis el velo, y sois del firmamento poesía.
63 fontaines de lumière dont 64 s'illumine le voile de la nuit, 65 vous êtes la poésie du firmament!

En los versos 52-65 se consigute la identidad emotiva del lector, con la triste grandeza de esas ruinas, tan propicias al stueño nostálgico como al rapto extático, por el hábil empleo de términos descriptivos y del imperfecto del verbo, los cuales hacen destacar el lento desenvolvimiento del día por las etapas sucesivas de tarde, crepúsculo y noche. El hecho de traducir en tanto por enfin y se fué tornando por devint, cambia el sentido y al mismo tiempo impide el correr rítmico de este poema "tan suavemente graduado en su majestuoso y reposado movimiento." " ${ }^{0}$ Habría tenido más éxito Ampère si se hubiera servido de ce pendant $\mathrm{y}$ de devenait, en vez de enfin y devint.

La imprudencia cometida por Ampère, al sustituir el Iztaccihuatl por el Orizaba, se echa de ver aún más claramente en los versos 58-59. Como no se puede ver siempre de día el Orizaba desde Cholula, es inverosímil que pudiera verse de noche la reflexión de la luna en la nieve del lejano volcán. Al parecer, el poeta in petto, que, según Sainte-Beauve, ${ }^{31}$ no dejaba nunca de señalar su presencia tan pronto como se hallaba Ampère en una zona arqueológica, llegó a imponerse con tan gran eficacia, que acabó el pobre por confundirlo todo, tanto la geografía como la distancia.

E1 hecho de que Ampère dejara sin traducir los versos 95-150; tal vez se deba a la crítica desfavorable que en ellos hace Heredia de la civilización azteca, tan admirada por el escritor francés. Veamos con cuanto éxito salió, en su traducción de los versos 66-95:

Al paso que la luna declinaba, y al ocaso fulgente descendía con lentitud, la sombra es extendía

del Popocatepec, y semejaba fantasma colosal. E1 arco obscuro

a mí llegó, cubrióme, y su grandeza. fué mayar y mayor, hasta que al cabo

en sombra universal veló la tierra.
66 A mesure que la lune s'abaissait

67 radieuse vers l'occident,

68 l'ombre du Pocatepetl (sic) s'etendait avec lenteur;

69 on eût dit

70 un gigantesque fantôme. L'arc tenebreux

71 vint jusqu'a moi et me cotvvrit ....

72 et il alla toujours grandissant jusqu'a ce qu'enfin

73. toute la terre fût enveloppée de son ombre. 
Volví los ojos al volcán sublime, 74 Je tournai les yetix vers le majestueux volcan

que velado en vapores transparentes,

75 qui, voile de transparentes vapeurs, sus inmensos contornos dibujaba de occidente en el cielo.

76 dessinait ses inmenses contours

¡ Gigante del Anáhuac! ¿ cómo el vtrelo de las edades rápidas no imprime alguna huella en tu nevada frente? Corre el tiempo veloz, arrebatando

años y siglos, como el norte fiero

precipita ante sí la muchedumbre de las olas del mar. Pueblos y reyes viste hervir a tus pies, que combatían

cual hora combatimos, y llamaban

eternas sus ciudades, y creían fatigar a la tierra con su gloria. Fueron: de ellos no resta ni memoria.

¿Y tú eterno serás? Tal vez un día

de tus profundas bases desquiciado caerás; abrumará tı grał rtiina

al yermo Anảhuac; alzaránse en ella

nuevas generaciones $y$ orgullosas que fuiste negarán...

77 a l'occident, sur le ciel.

78 Géant de l'Anahuac, comment le vol

79 rapide des âges n'imprime-t-il

80 aucune ride sur ton front de neige?

81 Le temps court impétueux, amoncelant

82 les années ct les siècles, comme le vent du nord

83 précipite devant lui la multitude

84 des ondes; ..............

85 tu as vu bouilloner à tes pieds les peuples et les rois, qui combattaient

86 comme nous combattons, et appelaient

87 letrs cités étemelles, et croyaient

88 fatiguer la terre de leur gloire.

89 Ils ont été! I1 n'en reste pas même un souvenir.

90 Et toi, seras-tu éeternel? Peut-être t1n jour,

91 arraché de ta base profonde,

$92 \mathrm{tu}$ tomberas; ta grande ruine attristera

93 l'Anáhuac solitaire; de nouvelles générations s'élèveront

$94 \ldots \ldots \ldots \ldots$ et, dans leur orgueil, 95 nieront que tu aies été!

Es de notar que Popocatepec (69), en la traducción de Ampère, pierde una sílaba. Al traducir arrebatando por anoncelant, que quiere decir amontonando, se modifica el concepto de Heredia de tal modo, que Ampère destruye en gran parte el efecto dramático del verbo arrebatar dándonos en su lugar la idea casi pasiva del amontonamiento del tiempo.

En cuanto a los vocablos attristera y solitaire itraducen bien abrumará (92) y yermo (93)? A mi parecer, el verso de Heredia significaría que las ruinas del volcán "agabiarán físicamente con su gran peso a Anáhuac abandonado e inculto", mientras que la traducción de Ampère querría decir, al contrario, que las grandes rui- 
nas "entristecerán a Anáhuac por faltarle sus antiguos habitantes." Pero la interpretación de Ampère no está desprovista de mérito.

De la simpatía y admiración de Ampère por el desgraciado $\mathrm{He}$ redia, cuya alma estaba llena "d'enthousiasme pour la liberté et d'horreur pour l'oppression", "32 participaba otro colaborador de $L a$ Revue des Deux Mondes. Se trata de Elisée Reclus. En un artículo titulado "Les Poètes sud-américains" publicado en dicha revista, en el número del 15 de febrero de 1864, Reclus tradujo en la siguiente forma versos de "En una tempestad", los cuales, afirma el traductor, "tous les américains savent par coeur." 33

Ouragan! ouragan! je te sens venir, et dans ton souffle brûlant je respire enivré l'haleine du maitre des airs. Voisle, suspendu aux ailes du vent, rouler à travers l'espace immense, silencieux encore, mais effrayant, irrésistible dans sa course. La terre, qu'opprime un calme sinistre et mystérieux, contemple avec stupeur le terrible météore... Le soleil hésitant voile sous de tristes vapeurs sa face glorieuse, et son disque obscurci répand une lueur funèbre qui n'est pas la nuit et qui n'est plus le jour. Lueur affreuse, voile de mort! les oiseaux tremblent et se cachent à l'approche de l'ouragan qui hurle; sur les montagnes lointaines, les forêts l'entendent et lui répondent.

Le voilà! Il étend sur la nature son manteau d'épouvante. Géant des airs, je te salue!... Le vent secoue et fait tournoyer les tranges mêlées de son vêtement sombre. Ses bras grandissans se dejoignent au-dessus de l'horizon; ils s'abaissent et recouvrent l'espace d'une montagne à l'autre.

Ténèbres partout! Le souffle de l'orage soulève en tourbillons la poussière des campagues. Dans les nues, la maitre du tonnerre fait rouler son char grondant; des roues jaillit le rapide éclair, qui vient frapper la terre et de ses reflets livides inonde le ciel... La pluie tombe à torrens. Tout est confusion, horreur profonde. Cieux, nuées, collines, forêt chérie, je vous cherche en vain; vous avez disparu. La noire tempête fait tournoyer dans les airs un océan sous lequel tout s'engloutit. Enfin, monde fatal, nous nous séparons! L'ouragan et moi, nous restons seuls ... 34

No se encuentran en la traducción de Reclus bastantes errores o disparates para justificar el cotejo de todo lo traducido con el original. Sin embargo, se destacan algunos, como se puede ver en lo siguiente, que ofrecemos sin comentarios. Basta decir que los 
cambios efectuados, sea adrede, sea por entender mal el sentido, sólo sirven para disminuir el elemento dramático y empañar el brillo de las imágenes.

........... La tierra en calma siniestra, misteriosa, contempla con pavor su faz terrible $\ldots \ldots \ldots \ldots \ldots$ E1 sol temblando Llega ya... ¿No le veis? ‘Cuál desenvuelve

su manto aterrador y majestuoso!

|Ved!... i En el horizonte

los brazos rapidísimos enarca

y con ellos abarca

cuanto alcanzo a mirar de monte a monte

En las nubes retumba despeñado el Carro del Señor, y de sus ruedas

brota el rayo veloz, se precipita, hiere y aterra al suelo, y su livida luz inunda al cielo. ¿Qué rumor? ¿Es la lluvia? Desatada cae a torrentes, obscurece el mundo
8 La terre, qu'opprime un calme

9 sinistre et mystérieux

10 contemple avec stupeur le terrible météore

16 Le soleil hésitant...

26 Le voilà! Il étend sur la nature

27 son manteau d'épouvante.

31

32 Ses bras grandissans se rejoignent

33 au dessus de l'horizon; ils s'abaissent

34 et recouvrent l'espace d'une montagne à l'autre

38 Dans les nues, le maître du

39 tonnere fait rouler son char grondant;

40 des rues jaillit le rapide éclair,

41 qui vient frapper la terre et

42 de ses reflets livides inonde le ciel.

$43 \mathrm{La}$ pluie tombe a torrens 44

Es de notar que se omiten de la traducción los versos 11-15 y parte de los versos siguientes: (16), "iQué nubes! ¡qué furor!"; (26) “¿No lo veis?”; (47) “¿ dó estáis?” Tampoco traduce Rechus la última estrofa (53-63), que expresa el sentimiento religioso experimentado por el poeta al presenciar la " $i$ sublime tempestad!" Se puede conjeturar que el traductor, indiferente al pensamiento filosófico del poeta, sólo se interesara por sus descripciones de la naturaleza y debido a ello la dejó sin traducir.

La profunda simpatía y admiración de Reclus por el desdichado Heredia y lo que simboliza, se confirman en el juicio siguiente:

Condamué au bannissement pour avoir trop aimé la liberté, il ne cessa jusqu'à sa mort prématurée de travailler à l'affranchissement de sa patrie et d'en peindre la beauté grandoise en vers d'une force rarement égalée. L'âme d'Heredia était d'une trempe 
héroique, et il ne faut point attribuer à the vaine jactance de poète les paroles qu'il adressait au Niagara: "Laisse-moi te regarder, je suis digne de te voir!" 35

¡Ojalá que Mazade también hubiera podido participar de los juicios simpáticos y justos de Reclus y de Ampère! Este concluyó sus comentarios sobre Heredia con las palabras: "puissent les lignes que je lui consacre ici commencent sa renommée en Europe!" 36 Desdichadamente no era así. En Francia y en Europa i sí que adquirieron su nombre y apellido fama y eminencia, pero no sus versos! Con el tiempo es de esperar que la vieja Europa llegue a apreciar en lo que vale al otro Heredia, el de habla española, y de tal modo que por fin pueda alcanzar, después de tantos años, el renombre europeo que le deseaba Jean Jacques Ampère hace un siglo.

\author{
Boyd G. CARTER, \\ University of Nebraska.
}

\title{
NOT A S
}

1 Véase: "Inauguration du monument à José Maria de Heredia", tomo 183, pp. 850-855. El autor de lo publicado en Echos que firma $D x$, se equivocó al inferir que el Heredia recomendado como "gran poeta" por Marceline Desbordes-Valmore en su carta de 1857, sería Heredia el mayor, el de habla castellana. Se trataba de otro Heredia, de nombre Severiano, primo segundo de los otros dos, también cubano y poeta. Este nació en 1836. Era hijo natural de Ignacio de Heredia, primo hermano de los padres de los dos ilustres poetas. Después de la muerte de su padre quedó Severiano al cuidado de su madre política, la señora Godefrois, francesa, quien le llevó a París, donde conoció a madame Desbordes-Valmore, gran poetisa y amiga de su madre por adopción. Además de ser poeta como sus primos - pero muy inferior a ellos eir talento-, se distinguió en Francia como político y ejerció las funciones de consejero municipal de París, de diputado y ministro de obras públicas en el ministerio Rouvrier. Murió en 1901. Véase: Max Henrique Ureña, "Poetas cubanos de expresión francesa", Revista Iberoamericana III, (mayo, 1941), $317-325$.

$D x$ se equivoca también, cuando dice al referirse al Heredia de habla española lo siguiente: "C'était un lyrique cubain mort en 1839 et célèbre pour son ode à l'ouragan ("En una tempestad") où il dit, parlant au Niagara: "Je suis digne de te contempler." Se encuentra el verso "yo soy digno de contemplarte" en "el Niágara". 
2 Véasc: tomo 184, pp. 769-772.

3 Ibid., p. 769.

4 Ibid., p. 768.

5 Ibid., p. 772.

6 Ibid., ‥ 769.

7 Véase: Letras, Obras completas, vol. vin, Madrid, Mundo Latino, 1918. Véase: "París y los escritores extranjeros", pp. 11-20.

8 Historia de la poessía hispanoamericana, p. 229.

9 En el número de diciembre de 1851, pp. 1017-1035.

10 Véase: "Promenade en Amérique. Le Mexique. I. Vera Cruz et Mexico", RDM 3 (1853) 1049-1075; II. "Les Antiquités, les mines et l'avenir du Mexique", 4 (1853) 87-117; III. "De Mexico d̀ Paris", 4 (1853) 201-231 (las páginas 213-214 se consağran a Heredia).

11 RDM 49 (1864) 902-927.

12 Véase: "De l'Américanisme et des Républiques du Sud", La Société argentine, Quiroga et Rosas (civilización: Barbarie, de M. Domingo Sarmien10), XVI (1846) 625-660.

13 Véase: "La société et la littérature a Cuba", RDM 4 (1851) 1017-1035.

14. Ibid., D. 1027.

15 Ibid.

16 Op. cit., p. 234.

17 "Jean Jacques Ampère", $R D M$ el $1^{\circ}$ de septiembre de 1868, p. 14.

18 Ibid, p. 28.

19 Ibid., p. 5.

20 Ibid., p. 40.

21 Ibid., p. 42.

22 Ibid., p. 8.

23 Book of Marvels, New York, 1941, p. 96.

24 Op. cit., p. 214.

25 No obstante, es de creer o por lo menos conjeturar, que Carpio no diera la siguiente nota biográfica tan errada como concisa "L'auteur de ces vers [se refiere al poema "En el Teocalli de Cholt1a"] était né à Caracas; une révolution l'amena enfant au Mexique. A la mort de son père, il alla vivre 
dans l'île de Cuba, où sa famille avait des biens; une autre révolution l'en chassa. Il voyagea dans les Etats-Unis et revint au Mexique, oǹ il mourut, à trente-deux ans, dans la ville de Toluca." Vol. rv, p. 214.

26 Ampère, op. cit., vol. Iv, p. 111.

27 Ibid., p. 213.

28 Ibid.

29 La siguiente cita deja ver la gran impresión que produjo el Orizaba al viajero francés: "Cette magnifique montagne que nous avons eu en perspective presque durant tout notre voyage au Mexique, et que nous avions déjà aperçue sur mer vingt-quatre heures avant d'aborder, est comme un grand phare naturel que les yeux rencontrent toujours, qui semble élevé dans la région des astres, et dominer, ainsi qu'eux, les scènes changeantes de la terre. Aujourd'hui de ce village, [San Agustín del Palmar] contemplé au coucher du soleil, l'Orizaba était particulièrement frappant. La cime de la montagne a pâli d'abord; on eût dit un fantôme blanc qui allait se dissoudre dans les airs; puis, au moment où le soleil descendait sous l'horizon, le neige du volcan a pris une teinte rosée. Le soleil n'était plus que là. Peu à peu sa lumière s'est retirée de ce dernier asile, et la gigantesque tête de la montagne s'est enfoncee dans la brume de la nuit." Ampère, op. cit., p. 215.

30 Menéndez y Pelayo, op. cit., p. 236.

31 Op. cit., p. 8.

32 Op. cit., p. 214.

33 Véase: "Les poètes sudaméricains", $R D M 49$ (janvier-février) 920.

34 Ibid.

35 Ibid.

36 Op. cit., p. 214. 